\title{
Perceptions of physicians and nurses concerning advanced care planning for patients with heart failure in Japan
}

\author{
Yuri Tokunaga-Nakawatase ${ }^{1}$, Ryota Ochiai $^{1}$, Makiko Sanjo $^{1}$, Miyuki Tsuchihashi-Makaya ${ }^{2}$, \\ Mitsunori Miyashita ${ }^{3}$, Toshiyuki Ishikawa ${ }^{4,5}$, Setsuko Watabe $^{1}$ \\ ${ }^{1}$ Department of Adult Nursing, Nursing Course, School of Medicine, Yokohama City University, Kanagawa, Japan; ${ }^{2}$ School of Nursing, Kitasato \\ University, Kanagawa, Japan; ${ }^{3}$ Department of Palliative Nursing, Health Sciences, Tohoku University Graduate School of Medicine, Miyagi, \\ Japan; ${ }^{4}$ Department of Cardiology, Yokohama City University Hospital, Kanagawa, Japan; ${ }^{5}$ Department of Cardiovascular Center, Yokohama City \\ University Medical Center, Kanagawa, Japan \\ Contributions: (I) Conception and design: All authors; (II) Administrative support: None; (III) Provision of study materials or patients: None; (IV) \\ Collection and assembly of data: Y Tokunaga-Nakawatase, R Ochiai, M Sanjo; (V) Data analysis and interpretation: All authors; (VI) Manuscript \\ writing: All authors; (VII) Final approval of manuscript: All authors. \\ Correspondence to: Yuri Tokunaga-Nakawatase. Department of Adult Nursing, Yokohama City University, 3-9 Fukuura, Kanazawa-ku, Yokohama 236- \\ 0004, Japan. Email: tokunaga@yokohama-cu.ac.jp.
}

Background: The importance of advance care planning (ACP) has been recognized in the palliative care of patients with heart failure. It is necessary for dissemination of ACP to characterize the perceptions of physicians and nurses towards ACP and to promote mutual understanding. The aim of this study is to investigate the perceptions of physicians and nurses concerning ACP for patients with heart failure.

Methods: We conducted a self-administered questionnaire survey with physicians and nurses who belonged to the 427 certified institutions for implantable cardioverter defibrillator (ICD) and/or cardiac resynchronization therapy (CRT) in Japan. The self-administered questionnaire was originally designed based on the guidelines on palliative care or ACP and previous studies on the barriers of ACP. We asked the participants the recognition about condition/timing to implement ACP, Content of care to be implemented in ACP, and barriers against implementing ACP. A Mann-Whitney $U$ test was performed and $r$ value was calculated an effect size (ES) in order to evaluate the characteristic perceptions among physicians and nurses. Results: Valid responses were obtained from 163 physicians (38.2\%) and 208 nurses (48.7\%). Regarding the condition/timing, nurses tended to recognize that ACP should be implemented from earlier clinical stages than physicians. Regarding the contents of ACP, both physicians and nurses placed emphasis in assessing the patient's perception of disease progression. The biggest difference was found in the item "Ask patient about what has been important in life so far"; $78.6 \%$ of physicians but $94.2 \%$ of nurses chose "it must/should be implemented" (Cohen's $r=0.31$ ). Regarding the barriers, both physicians and nurses recognized the difficulty in prognosis prediction. The biggest differences were found in the items "Medical staff does not know how to implement ACP for patients and their families" (45.6\% of physicians and 70.4\% of nurses chose "strongly agree/agree", $\mathrm{r}=0.27$ ), and "There is disagreement regarding care goals among team members of different professions" (18.5\% in physicians and $43.3 \%$ in nurses, $\mathrm{r}=0.27$ ).

Conclusions: It is suggested that discussions and further studies are necessary concerning the condition/ timing of implementing ACP from early stages, specific manuals/protocols and recommendation on rolesharing within a multidisciplinary team.

Keywords: Heart failure (HF); advance care planning (ACP); perception; physicians; nurses

Submitted Dec 27, 2019. Accepted for publication Apr 09, 2020.

doi: 10.21037/apm-19-685

View this article at: http://dx.doi.org/10.21037/apm-19-685 


\section{Introduction}

The number of patients with heart failure (HF) is rapidly growing in Japan as society ages. The number is predicted to increase to 1.3 million in 2030 (1) and it is of concern that an 'HF pandemic' may take place with a large increase in the number of aged patients with $\mathrm{HF}$ (2). A patient with HF has slowly deteriorating body functions, experiencing cycles of exacerbation and remission (3). Since the patient's condition may suddenly change, it is difficult to define the end of life stage in HF. In some cases, use of a ventilator, hemodialysis or a ventricular assist device (VAD) is effective, which makes a decision on discontinuing life-prolonging medical treatment or Do-Not-Attempt-Resuscitation (DNAR) difficult.

Recently, the importance of advance care planning (ACP) has been recognized in the palliative care of patients with HF. In 2012, the American Heart Association (AHA) released a statement recommending active ACP for patients with HF in the end of life stage (4). ACP is described as the overall process of discussing the wishes of patients and their families for specific treatments and living arrangements, which should be discussed with medical staff before a patient's decision-making ability is impaired; the goal of ACP is to provide measures for such patients to live satisfying lives at the end of life stages (5).

A number of interventional studies including randomized controlled trials (RCT) have been performed primarily in western countries and the effectiveness of ACP for patients with HF has been demonstrated. ACP by well-trained facilitators was reported to enable patients and their families to make decisions continuously (6). Meanwhile, ACP for patients with acute $\mathrm{HF}$ was reported not to enhance patients' anxiety and distress (7). In addition, patients who had undergone video-assisted ACP were shown to have a higher tendency to refrain from receiving life-prolonging medical treatments when compared to those using checklists (8). It was also reported that the level of satisfaction of patients with $\mathrm{HF}$ was increased when online support tools for ACP were used (9).

While the advantage of ACP has been reported, ACP for patients with HF and their families is not yet widespread even in western countries $(10,11)$. It is reported that the reasons for insufficient use of ACP are: physicians are too busy (12); prognosis of HF is difficult to predict; communication between physician and patient is insufficient; patients and their families are not able to accept their situation (13-15). In addition, while implementing ACP for patients with HF and their families' needs multidisciplinary collaboration among medical staff (13), physicians and nurses have different perceptions about (I) the reasons why discussion is difficult between patients/ families and medical staff concerning the goals of treatments in implementing ACP, (II) methods of participating in support for decision making, and (III) the roles of different medical professionals (16). A survey of cardiologists in Canada reported that differences of opinions among members of a multidisciplinary medical team are a barrier against implementing ACP (14). Since the most important professions of such multidisciplinary team are physicians and nurses (17), it is necessary for dissemination of ACP to characterize the perceptions of physicians and nurses towards ACP and to promote mutual understanding.

In Japan, physicians and nurses are ready and willing to carry out end of life care of patients with HF but they lack experience (18). Nationwide surveys on the present situation of palliative care for HF showed that over $80 \%$ of the physicians and nurses discussed their understanding of the disease and prognosis with the patients and/or their families in their facilities (19). In addition, a previous study on outcomes for palliative care for HF suggested including the category of ACP (20). However, these studies concerned palliative care for $\mathrm{HF}$ in general and not specifically in relation to ACP. Regarding ACP, implementation reports, case reports and commentaries have been published but to the best of our knowledge, research papers specific to ACP have not yet appeared in Japan. In Japan, where an ' $\mathrm{HF}$ pandemic' may occur, accumulation of evidence concerning ACP and dissemination of ACP are urgent tasks. In this study, we have investigated the perception of physicians and nurses about the necessity of and barriers to implementing ACP for patients with HF and their families in order to promote mutual understanding of medical staff members concerning ACP.

\section{Methods}

\section{Participants}

Self-administered questionnaires were mailed to all the 427 certified institutions (as of Nov. $1^{\text {st }}, 2016$ ) for implantable cardioverter defibrillator (ICD) and/or cardiac resynchronization therapy (CRT), which were thought to have rich experience in the care of patients with severe HF. Among the physicians and nurses in each institution, one cardiologist and one nurse working in a cardiology ward, who were expected to handle a large number of $\mathrm{HF}$ cases and to be most actively involved in ACP, were nominated by 
A housebound 68 years old patient with advanced CHF (NYHA class IV symptoms at baseline, LVEF $=20 \%$ with an CRT-D in place), who requires assistance for most activities of daily living, is admitted to the cardiology ward under your care with an exacerbation of his/her CHF. The patient's acute symptoms have been resolved. You are uncertain about the patient's goals of care and pref-erences regarding the use (or non-use) of life-sustaining technology.

Figure 1 The vignette presented in this study. CHF, chronic heart failure; NYHA, New York Heart Association Functional Class; LVEF, left ventricular ejection fraction; CRT-D, cardiac resynchronization therapy-defibrillator.

the director of the cardiology department and the director of nursing, respectively.

\section{Data collection}

A survey prospectus was sent to the director of the cardiology department and the director of nursing in each institution together with a prospectus for the nominees, a self-administered questionnaire and return envelope. The directors who agreed to the study nominated a physician and a nurse, and handed them the above-mentioned documents. When the nominees agreed to participate in the survey, they filled in the questionnaire and returned it to the authors. The survey was conducted in February and March, 2018.

\section{Measurements}

The self-administered questionnaire was originally designed based on the guidelines published in Europe (21), the US $(4,22)$ and Japan $(5)$ on palliative care or ACP, and previous studies on the barriers of ACP (12-15). We also conducted a focus group interview with 4 certified nurses in chronic $\mathrm{HF}$ nursing. On the basis of the guidelines and results of the interview, 5 nursing researchers in the field of cardiovascular nursing (MM, RO, YT) and cancer palliative care (MM, MS) discussed and verified the contents of the questionnaire (https://cdn.amegroups.cn/static/public/apm-19-685-1.pdf; https://cdn.amegroups.cn/static/public/apm-19-685-2.pdf).

\section{Condition/timing to implement ACP for patients with beart failure}

Regarding the patients' condition/timing where ACP is deemed necessary, we identified 10 conditions such as: 'patients diagnosed as heart failure for the first time', 'patients with a record of hospitalization more than twice a year', 'patients in NYHA IV and requiring frequent/ continuous infusion pharmacotherapy', and others. For each item, participants were asked to answer on a 5 -point Likert scale from 'ACP must be implemented' to 'ACP must not be implemented'.

\section{Content of care to be implemented in ACP for patients with beart failure}

Regarding the perception of the content of care to be implemented in ACP for patients with HF, the vignette shown in Figure 1 was used. The vignette was based on that used in a previous Canadian study on the barriers and solutions of physicians and nurses to improve communication and decision-making about goals of care for hospitalized patients with advanced HF (16). The vignette used in the Canadian study has NYHA class IIIIV symptoms at baseline and had an ICD in place. In this study, the patient in the vignette has NYHA class IV symptoms at baseline and a CRT-D in place. It was intended that the vignette would recall the need for ACP in Japan. Participants were asked to answer the 13 items that were to be considered for implementation as ACP on a 5-point Likert scale from 'it must be implemented' to 'it must not be implemented', if they were in charge of the patient. Items were 'Ask patient about how he/she perceives the heart failure progression', 'Ask patient whom he/she would prefer to help them in making decisions when he/she becomes unable to do so', and others.

\section{Barriers against implementing $A C P$}

Concerning the barriers against implementing ACP for patients with HF, items were such as 'The prognosis is difficult to predict', 'Family members cannot accept patients' poor prognosis'. In each item, participants were asked to answer on a 5 -point Likert scale from 'strongly agree' to 'strongly disagree'.

\section{Characteristics of institutions}

Regarding the characteristics of the institution, we collected the following data on a nominal scale; total bed number; if they were a: cardiovascular center; advanced treatment hospital; certified institution for VAD; certified institution for transcatheter aortic valve implantation (TAVI); certified institution for heart transplantation; having coronary care unit (CCU); having palliative care team (PCT); having 
multidisciplinary conference for patients with HF; having nurse-led outpatient for patients with HF; having certified nurses in chronic HF nursing; having certified nurses in palliative care.

\section{Characteristics of participants}

We asked the participants their sex, age and the number of HF cases in their charge during the last 30 days. Physicians were asked for the number of years after becoming a boardcertified cardiologist and for their subspecialty. Nurses were asked the number of years of clinical experience, the number of years of experience in a cardiology ward, position and qualification.

\section{Statistical analysis}

For the characteristics of participants, descriptive statistics were calculated. Concerning recognition of the condition/ timing of patients with $\mathrm{HF}$ who need ACP, content of care to be implemented in ACP and barriers against implementing ACP, descriptive statistics were calculated for physicians and for nurses separately. A Mann-Whitney $\mathrm{U}$ test was performed and $\mathrm{r}$ value was calculated an effect size (ES) in order to evaluate the characteristic perceptions among physicians and nurses. Statistical analyses were done using IBM SPSS Statistics version 22.0 for Microsoft Windows. The statistical significance level was set at $5 \%$.

\section{Ethical consideration}

The present study was performed after obtaining the permission of the Yokohama City University Bioethics Committee for Human Genome and Gene analysis (November 7, 2017; approval number, A171100002) and written informed consent was obtained from all participants.

\section{Results}

\section{Background of participants (Tables 1,2,3)}

Out of 427 physician nominees and 427 nurse nominees, valid responses were obtained from 163 physicians and 208 nurses (valid response rate: $38.2 \%$ and $48.7 \%$, respectively). Of these, 150 physicians $(92.0 \%)$ and 23 nurses $(11.1 \%)$ were male $(\mathrm{P}<0.0001)$. Sixty-four physicians $(39.3 \%)$ and 112 nurses $(53.8 \%)$ were under 40 years of age $(\mathrm{P}<0.0001)$. Concerning the number of $\mathrm{HF}$ cases dealt with during the last 30 days, $16.0 \%$ of physicians answered that they had been in charge of $\geq 11$ 'patients with left ventricular ejection fraction (LVEF) $\leq 20$ when hospitalized', while among nurses, the proportion was $8.7 \%(U=12,804.5$, $Z=-4.30, \mathrm{P}<0.0001, \mathrm{ES}=0.22)$. Among nurses, $8.7 \%$ answered that they had been in charge of $\geq 11$ 'patients with a record of hospitalization more than twice a year,' while among physicians, the proportion was $10.4 \%(U=14,794.0$, $Z=-2.05, \mathrm{P}=0.041, \mathrm{ES}=0.11$ ).

\section{Condition/timing to implement ACP for patients with beart failure (Table 4)}

The condition/timing where the highest proportion of physicians as well as nurses answered 'ACP should be implemented' or 'ACP must be implemented' was found for 'patients clinically judged to be close to the end of life stages'. The second largest percentage was seen among physicians (95.7\%) who chose the answer 'ACP should be implemented' or 'ACP must be implemented' for 'patients who need nearly all types of care for daily life due to deterioration of physical/mental functions,' while the second biggest percentage was seen among nurses (94.7\%) who chose the answer 'patients in NYHA IV and requiring frequent/continuous infusion pharmacotherapy'.

Significantly higher proportions were found with nurses than physicians who chose the answer 'ACP should be implemented' or 'ACP must be implemented' in four out of ten items. Nurses tended to answer that ACP should be implemented early such as at the time of diagnosis of $\mathrm{HF}$ or first hospitalization for HF. A small difference was seen in the item 'patients with LVEF $\leq 20$ when hospitalized': $62.6 \%$ of physicians but $85.1 \%$ of nurses chose 'ACP should be implemented' or 'ACP must be implemented' $(U=11470.5, Z=-5.70, \mathrm{P}<0.0001, \mathrm{ES}=-0.30)$.

\section{Content of care to be implemented in ACP (Table 5)}

The highest proportions for choosing 'it must be implemented' or 'it should be implemented' were seen with physicians $(96.3 \%)$ and nurses $(97.6 \%)$ with the item 'Ask patient about how he/she perceives the heart failure progression.' The second biggest percentage was found with physicians (94.5\%) for the item 'Ask patient whom he/ she would prefer to help them in making decisions when he/she becomes unable to do so,' while the second biggest percentage with nurses (95.1\%) was found for the item 'Ask patient to what extent he/she would like to know about 
Table 1 Background of participants' institutions

\begin{tabular}{|c|c|c|c|c|c|}
\hline Characteristics & \multicolumn{2}{|c|}{ Physicians ( $n=163$ ) } & \multicolumn{2}{|c|}{ Nurses $(n=208)$} & $\mathrm{P}$ \\
\hline Total bed number & & & & & 0.679 \\
\hline 20-99 & 6 & 3.7 & 11 & 5.3 & \\
\hline $100-199$ & 8 & 4.9 & 8 & 3.8 & \\
\hline 400 or more & 125 & 76.7 & 151 & 72.6 & \\
\hline NA & 3 & 1.8 & 5 & 2.4 & \\
\hline Cardiovascular center & 45 & 27.6 & 70 & 33.7 & 0.200 \\
\hline Advanced treatment hospital & 100 & 61.3 & 114 & 54.8 & 0.185 \\
\hline Having CCU & 121 & 74.2 & 127 & 61.1 & 0.011 \\
\hline Having PCT & 137 & 84.0 & 174 & 83.7 & 0.894 \\
\hline Having multidisciplinary conference for patients with HF & 127 & 77.9 & 156 & 75.0 & 0.547 \\
\hline Having the Nurse-led outpatient for patients with HF & 26 & 16.0 & 32 & 15.4 & 0.873 \\
\hline Having $\mathrm{CN}$ in chronic heart failure nursing & 91 & 55.8 & 99 & 47.6 & 0.111 \\
\hline Having $\mathrm{CN}$ in palliative care & 129 & 79.1 & 172 & 82.7 & 0.464 \\
\hline
\end{tabular}

Questions were answered by the participants by yes/no, except for "total bed number". NA, no answer; CCU, coronary care unit; VAD, ventricular assist device; TAVI, transcatheter aortic valve implantation; PCT, palliative care team; HF, heart failure; CN, certified nurse.

Table 2 Background of participants

\begin{tabular}{|c|c|c|c|c|c|}
\hline Characteristics & \multicolumn{2}{|c|}{ Physicians $(n=163)$} & \multicolumn{2}{|c|}{ Nurses $(n=208)$} & $\mathrm{P}$ \\
\hline Sex: male & 150 & 92.0 & 23 & 11.1 & $<0.0001$ \\
\hline \multicolumn{6}{|l|}{ Age } \\
\hline$\leq 30$ s & 64 & 39.3 & 112 & 53.8 & $<0.0001$ \\
\hline $50 \mathrm{~s}$ & 33 & 20.2 & 17 & 8.2 & \\
\hline$\geq 60$ s & 4 & 2.5 & 0 & 0.0 & \\
\hline \multicolumn{6}{|c|}{ Years after becoming a board-certified cardiologist } \\
\hline Not qualified yet & 35 & 21.5 & & & \\
\hline $15-19$ & 23 & 14.1 & & & \\
\hline
\end{tabular}

Table 2 (continued) 
Table 2 (continued)

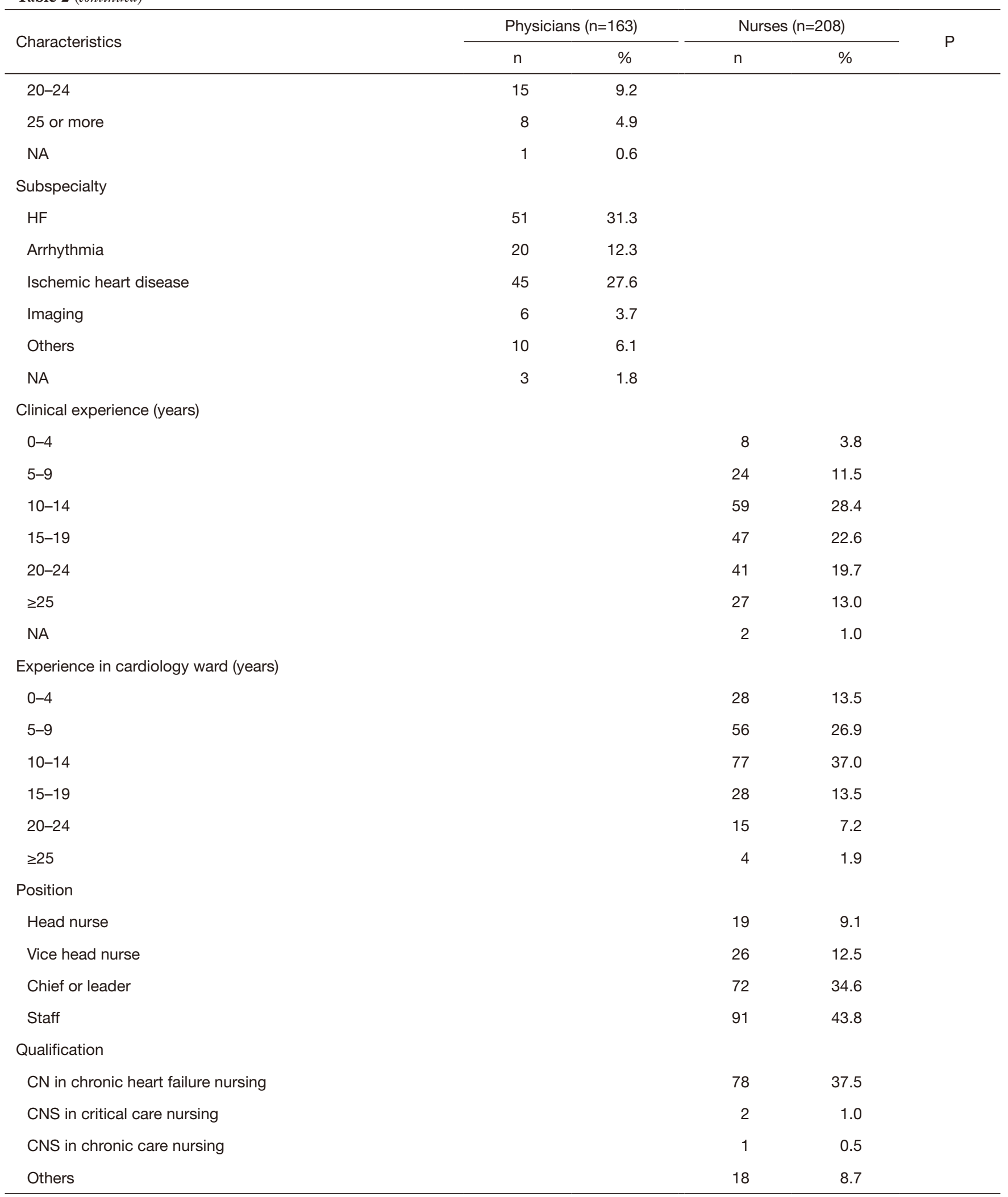

$\mathrm{NA}$, no answer; HF, heart failure; CN, certifierd nurse; CNS, certified nurse specialist. 


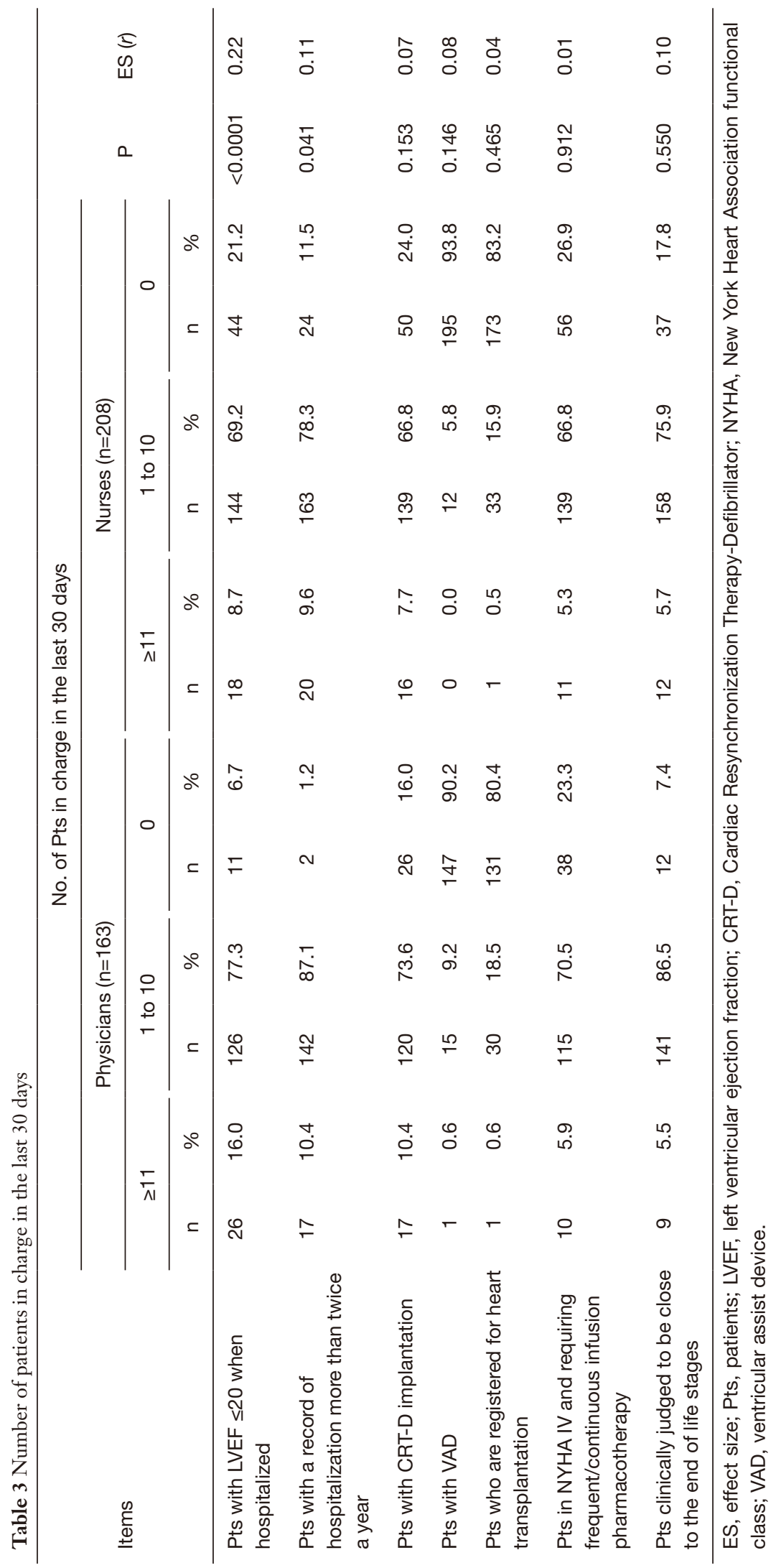


Table 4 Condition/timing to implement ACP

\begin{tabular}{|c|c|c|c|c|c|c|c|c|}
\hline Items & \multicolumn{2}{|c|}{$\begin{array}{l}\text { Physicians ( } \mathrm{n}=163) \text {, } \\
\text { 'ACP must/should be } \\
\text { implemented' }\end{array}$} & \multicolumn{2}{|c|}{$\begin{array}{l}\text { Nurses }(n=208), \\
\text { 'ACP must/should be } \\
\text { implemented' }\end{array}$} & $U$ & Z & $P$ & $\mathrm{ES}(r)$ \\
\hline $\begin{array}{l}\text { Pts diagnosed as heart } \\
\text { failure for the first time }\end{array}$ & 26 & 16.0 & 48 & 23.1 & $13,566.0$ & -3.49 & $<0.0001$ & -0.18 \\
\hline $\begin{array}{l}\text { Pts with LVEF } \leq 20 \text { when } \\
\text { hospitalized }\end{array}$ & 102 & 62.6 & 177 & 85.1 & $11,470.5$ & -5.70 & $<0.0001$ & -0.30 \\
\hline $\begin{array}{l}\text { Pts with a record of } \\
\text { hospitalization more than } \\
\text { twice a year }\end{array}$ & 120 & 73.6 & 168 & 80.7 & $15,544.0$ & -1.40 & 0.163 & -0.07 \\
\hline Pts with VAD & 128 & 78.4 & 180 & 86.3 & $15,552.0$ & -1.28 & 0.200 & -0.07 \\
\hline $\begin{array}{l}\text { Pts who are registered for } \\
\text { heart transplantation }\end{array}$ & 126 & 77.1 & 184 & 88.7 & $15,280.0$ & -1.59 & 0.111 & -0.08 \\
\hline $\begin{array}{l}\text { Pts requiring nearly all } \\
\text { types of cares for daily } \\
\text { life due to deterioration of } \\
\text { physical/mental functions }\end{array}$ & 156 & 95.7 & 189 & 90.9 & $16,140.5$ & 0.81 & 0.421 & 0.04 \\
\hline $\begin{array}{l}\text { Pts in NYHA IV and } \\
\text { requiring frequent/ } \\
\text { continuous infusion } \\
\text { pharmacotherapy }\end{array}$ & 156 & 95.7 & 197 & 94.7 & $16,877.5$ & 0.09 & 0.926 & 0.00 \\
\hline
\end{tabular}

ACP, Advance Care Planning; ES, effect size; Pts, patients; NYHA, New York Heart Association functional class; VAD, ventricular assisst device; LVEF, left ventricular ejection fraction; CRT-D, cardiac resynchronization therapy-defibrillator.

treatment in the following days/months'.

Significantly higher proportions of nurses chose 'it must be implemented' or 'it should be implemented' in 10 out of 13 items than physicians. A medium difference was found in the item 'ask patient about what has been important in life so far': $78.6 \%$ of physicians but $94.2 \%$ of nurses chose 'it must be implemented' or 'it should be implemented' ( $\mathrm{U}=11,389.0, Z=-5.92, \mathrm{P}<0.0001, \mathrm{ES}=-0.31$ ). A small difference was seen with the item 'Ask patient about what kind of life he/she would like to live from now on'; $87.7 \%$ of physicians but $92.3 \%$ of nurses chose 'it must be implemented' or 'it should be implemented' ( $\mathrm{U}=12,735.0$, $Z=-4.69, \mathrm{P}<0.0001, \mathrm{ES}=-0.24)$.

\section{Barriers against implementing ACP (Table 6)}

It was revealed that $76.7 \%$ of physicians and $85.4 \%$ of nurses chose 'strongly agree' or 'agree' for the item 'The prognosis is difficult to predict' to be a barrier against implementing ACP. The second highest proportions of choosing 'strongly agree' or 'agree' were found with the item 'Patients cannot accept their poor prognosis' with $63.2 \%$ of physicians and $71.3 \%$ of nurses.

Significantly higher proportions of 'strongly agree' or 'agree' in 4 out of 12 items were found with nurses than physicians. A small difference was seen for the item 'Medical staff does not know how to implement ACP for patients and their families': $45.6 \%$ of physicians and $70.4 \%$ of nurses 
Table 5 Contents of care to be implemented in ACP

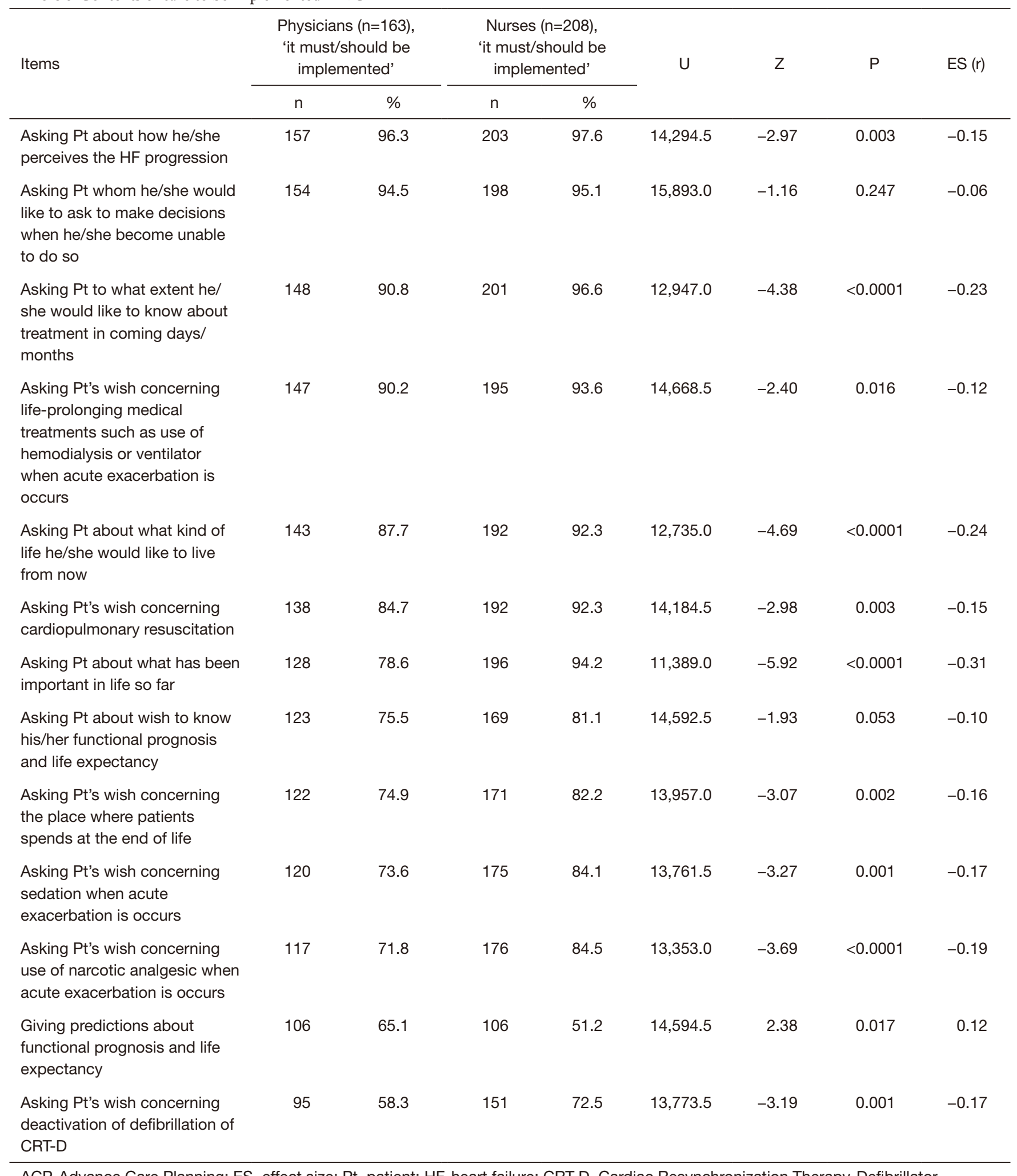

ACP, Advance Care Planning; ES, effect size; Pt, patient; HF, heart failure; CRT-D, Cardiac Resynchronization Therapy-Defibrillator. 
Table 6 Barriers against implementing ACP

\begin{tabular}{|c|c|c|c|c|c|c|c|c|}
\hline Items & \multicolumn{2}{|c|}{$\begin{array}{l}\text { Physicians }(\mathrm{n}=163) \\
\text { 'strongly agree' or } \\
\text { 'agree' }\end{array}$} & \multicolumn{2}{|c|}{$\begin{array}{l}\text { Nurses ( } \mathrm{n}=208) \text {, } \\
\text { 'strongly agree' or } \\
\text { 'agree' }\end{array}$} & $U$ & Z & $\mathrm{P}$ & $E S(r)$ \\
\hline Uncertainty in predicting prognosis & 125 & 76.7 & 178 & 85.4 & $14,443.5$ & -2.49 & 0.013 & -0.13 \\
\hline $\begin{array}{l}\text { Pt's difficulty in accepting poor } \\
\text { prognosis }\end{array}$ & 103 & 63.2 & 148 & 71.3 & $15,815.0$ & -1.03 & 0.305 & -0.05 \\
\hline $\begin{array}{l}\text { Family members' difficulty in accepting } \\
\text { poor prognosis }\end{array}$ & 93 & 57.0 & 129 & 62.2 & $14,983.0$ & -1.87 & 0.062 & -0.10 \\
\hline $\begin{array}{l}\text { Pt's difficulty in imagining possible life- } \\
\text { prolonging medical treatments in the } \\
\text { future }\end{array}$ & 92 & 56.5 & 122 & 58.7 & $15,479.0$ & -1.36 & 0.174 & -0.07 \\
\hline $\begin{array}{l}\text { Family members' difficulty in imagining } \\
\text { possible life-prolonging medical } \\
\text { treatments in the future }\end{array}$ & 88 & 54.0 & 112 & 53.9 & $16,208.0$ & -0.60 & 0.548 & -0.03 \\
\hline $\begin{array}{l}\text { Medical staff's desire to give hope to } \\
\text { Pts and their families }\end{array}$ & 76 & 46.9 & 67 & 32.2 & $14,273.0$ & -2.44 & 0.015 & -0.13 \\
\hline $\begin{array}{l}\text { Medical staff's uncertainty how to } \\
\text { implement ACP for Pts and their } \\
\text { families }\end{array}$ & 74 & 45.6 & 146 & 70.4 & $11,730.0$ & -5.13 & $<0.0001$ & -0.27 \\
\hline
\end{tabular}

ACP, Advance Care Planning; ES, effect ize; Pts, patients.

chose 'strongly agree' or 'agree' $(\mathrm{U}=11,730.0, \mathrm{Z}=-5.13$, $\mathrm{P}<0.0001, \mathrm{ES}=-0.27)$. A small difference was found with the item 'There is disagreement regarding care goals among team members of different professions': $18.5 \%$ of physicians and $43.3 \%$ of nurses chose 'strongly agree' or 'agree' $(\mathrm{U}=11,723.5, \mathrm{Z}=-5.12, \mathrm{P}<0.0001, \mathrm{ES}=-0.27)$.

\section{Discussion}

This is the first study to investigate the perceptions of physicians and nurses in Japan concerning ACP for patients with $\mathrm{HF}$ and their families. Important findings of this study are the following: First, concerning the condition/timing of implementing ACP, both physicians and nurses recognized that ACP should be implemented mostly at the end of life stage but not at early stages such as first diagnosis as HF and first admission. Secondly, both physicians and nurses were found to place emphasis on collecting information about the progression and perception of the disease severity, while nurses placed particular emphasis on patients' sense of values. Thirdly, both the physicians and nurses recognized the difficulty in prognosis prediction as a barrier against implementing ACP, while the nurses raised a point that there was uncertainty among medical staff as to how to implement ACP and disagreement about care goals among multidisciplinary team members. These three findings are 
elaborated in the following section.

\section{Condition/timing of patients with HF who need ACP}

More than $90 \%$ of physicians and nurses chose 'ACP should be implemented' or 'ACP must be implemented' for the items where patients were clinically judged to be close to the end of life stage, need nearly all types of care for their daily life, and show symptoms of chronic NYHA IV in spite of appropriate treatments. These conditions correspond to Stage D heart failure, where the American College of Cardiology Foundation (ACCF)/American Heart Association (AHA) guidelines recommend considering palliative care as one of the treatment options (22). Since these items evoke images of patients at the end of life stage, the participants of this study tended to choose the answer 'ACP should be implemented' or 'ACP must be implemented'.

On the other hand, relatively few physicians and nurses chose 'ACP should be implemented' or 'ACP must be implemented' for the items concerning patients immediately after diagnosis as HF and first hospitalization. In the US (4), it is recommended that the time to consider implementing ACP is during a regular outpatient visit (once a year) and the time of discharge from hospital if 'milestones' appear that prompt reassessment during the clinical progression after hospitalization. Whereas implementing ACP from early stages is considered to be important, the participants in this study were found to show a rather negative attitude toward implementing ACP from early stages.

The Japanese guidelines for treatments of acute and chronic HF recommend starting ACP before the patient's condition worsens with deterioration of decisionmaking ability. However, no recommendations have been issued in Japan concerning specific condition/timing for implementing ACP at early stages. As for specific condition/ timing, 'patients with a record of hospitalization more than twice a year' could be screened rather easily and this is regarded as an index of advanced HF but not necessarily end of life stage; hence this may be considered an index for starting implementation of ACP. Although in this study, less than $50 \%$ of both physicians and nurses chose 'ACP should be implemented' for 'patients who are hospitalized for the first time', the US (4) regards hospitalization as a milestone where consideration of implementing ACP is triggered. Since the first hospitalization is an important clinical event for patients, it would be worth considering implementation of ACP at relatively early stages.

\section{Content of care to be implemented in ACP}

Concerning the fictitious patient with severe HF described in the vignette, high percentages for choosing 'ACP should be implemented' or 'ACP must be implemented' were items concerning the perception of HF progression, the hopes of surrogate decision makers, and what the patient wants to know about treatment. It is proposed that ACP for patients with $\mathrm{HF}$ and their families should be implemented with four steps: (I) to set up the place and participants; (II) to confirm what the patient knows and wants to know; (III) to confirm goals and intentions; and (IV) to consider treatments and decision based on the goals (4). The highest percentages of both the physicians and nurses who chose 'ACP should be implemented' were seen with the items corresponding to early steps of ACP.

On the other hand, for the items corresponding to the steps (III) and (IV) such as 'Ask about patient's wish concerning deactivation of cardiac resynchronization therapy-defibrillator' and 'Provide predictions concerning functional prognosis and life expectancy,' the percentages of physicians and nurses choosing 'ACP should be implemented' or 'ACP must be implemented' were found to be relatively low (51-74\%), although these items are to be considered at end of life stages (22). A possible reason for this is that treatment goals and wish of use/non-use of life support equipment of patients in the vignette were not shown in detail. Before discussing specific treatment plans/goals with patients, it is considered appropriate to collect information concerning the patient's perception of the disease trajectory and contents of decision making as discussed (4). The result of this study indicates the importance of information collection and assessment.

Nurses tended to choose 'ACP should be implemented' or 'ACP must be implemented' more than physicians in the items concerning the patient's sense of values. It is proposed that linking the care plan and preference/sense of values/goals of a patient is important in implementing ACP (23). The primary purpose of implementing ACP is to share a sense of values/life/death of patients with medical staff in addition to advance directives, according to Japanese guidelines (5). Nurses are expected to play roles in clarifying the extent of comprehension and sense of values of patients and their families in supporting decision-making by patients at the end of life stage (24). The participants of this study, both the physicians and nurses, regarded items important such as patients' history/progression of disease and comprehension of disease states, while the nurses were 
found to place particular importance on patients' sense of values. For dissemination of ACP in Japan, it is necessary that specific steps and procedures in implementing ACP and role-sharing should be clarified and reflected in educational programs for medical staff.

\section{Barriers against implementing $A C P$}

Concerning barriers against implementing ACP for patients with HF, high percentages of both physicians and nurses chose the answer 'strongly agree' or 'agree' on the items 'The prognosis is difficult to predict' and 'Patients cannot accept their poor prognosis'. A Japanese nation-wide survey (19) on palliative care for patients with HF raised the reason for hindering palliative care as the difficulty in prognosis prediction. A Canadian study (15) reported that denial of poor prognosis by patients and their families was a severe barrier in providing decision-making support by physicians and nurses. It is possible to ameliorate HF, once observed and diagnosed, by appropriate treatments while a patient may experience acute exacerbation or even die suddenly, which makes prognosis of HF difficult.

Perception of prognosis by patients and their families is regarded as important in implementing ACP since it leads to consideration of the future. As for HF, where prognosis prediction is difficult, prognosis scores have been developed such as the Seattle HF Model (SHFM). Nonetheless, models like SHFM may not be suitable for prognosis of individuals, even though they may be appropriately applied to a group of patients. For patients with $\mathrm{HF}$, judgement of the timing of implementation of ACP by evaluating the disease condition of individuals is considered to be difficult. About $50 \%$ of patients with $\mathrm{HF}$ die within 5 years after first diagnosis and the mortality rate within one year of hospitalized patients with HF is reported to be $37 \%$. Therefore, in order to disseminate ACP while overcoming the barrier that prognosis prediction is difficult, the following should be important, beneficial and effective in implementing ACP: (I) to start with consideration of implementing ACP by paying attention to turning points such as first diagnosis and first hospitalization, and (II) to enlighten and educate medical staff to facilitate the comprehension of patients and their families concerning the trajectory of HF.

Items for which relatively large differences were seen between the answers of physicians and nurses were lack of knowledge of ACP methods and disagreement among the healthcare team members about the goals of care; more nurses chose the answer 'strongly agree' or 'agree' than physicians. A previous study (18) on the perception of end of life care for patients with HF in Japan raised the difficulty in introducing palliative care due to factors like the unavailability of standards such as guidelines. In addition, this study revealed that nurses recognized differences of opinions within the multidisciplinary medical team concerning goals of treatments as a barrier in implementing ACP more strongly than physicians. In a previous study (25) on differences of opinion in intensive care unit (ICU) care, nurses noticed conflicts of opinions more frequently than physicians, in agreement with the result of this study. It is important to enhance communication among different professions, for example by means of conferences and information sharing in implementing ACP.

\section{Limitations}

This study has the following limitations: first, there may be selection bias. The participants were limited to physicians and nurses of certified ICD/CRT institutions in Japan. It is thought that certified ICT/CRT institutions handle a large number of patients with severe HF, but this study did not investigate the perceptions of physicians and nurses at other institutions. In addition, the participation rate was less than $50 \%$ (38\% of physicians and $49 \%$ of nurses) so the study might be biased towards those professionals who have a greater interest in ACP. Secondly, the vignette used in the present study focuses on one time point of the entire trajectory without describing in detail the disease history/progression. In spite of these limitations, this study is the first to reveal the perceptions of physicians and nurses implementing ACP for patients with HF and their families, and we believe it contributes to advancing the implementation of ACP for patients with HF and their families in Japan.

We hope to perform a further study on physicians and nurses from more institutions to permit further generalization. We will also evaluate the present situation of ACP implementation and needs of patients and their families for developing policies and strategies for advancing ACP implementation in Japan. Furthermore, evaluation is expected of the effects of implementing ACP for patients with $\mathrm{HF}$ and their families in this country.

\section{Conclusions}

This study investigated the perception of physicians and 
nurses on the necessity of and barriers against implementing ACP for patients with HF and their families. The study revealed the following three points: (I) concerning the condition/timing of implementing ACP, both physicians and nurses had a relatively negative attitude towards ACP at early stages or at the very end of life stage. (II) Concerning the content of ACP implementation, both physicians and nurses were found to place emphasis on assessing the patient's perception of the progression of HF. In addition, nurses placed particular emphasis on the patients' sense of values. (III) Concerning the barriers against implementing ACP, both physicians and nurses raised the difficulty of prognosis prediction. Nurses also considered that disagreement of opinions among different professions were a barrier and that specific methods for implementing ACP were not clear.

Discussions and further studies are necessary concerning the condition/timing of implementing ACP from early stages, specific manuals/protocols and recommendation on role-sharing within a multidisciplinary team.

\section{Acknowledgments}

We express our gratitude to all the participants in the study. Funding: This study was supported by the grant for 20162017 Research Development Fund (Nos. WJ 2811) of Yokohama City University.

\section{Footnote}

Conflicts of Interest: All authors have completed the ICMJE uniform disclosure form (available at http://dx.doi. org/10.21037/apm-19-685). MM serves as an unpaid editorial board member of Annals of Palliative Medicine from Jul 2019 to Jun 2021. The other authors have no conflicts of interest to declare.

Ethical Statement: The authors are accountable for all aspects of the work in ensuring that questions related to the accuracy or integrity of any part of the work are appropriately investigated and resolved. All procedures followed were in accordance with the ethical standards of the responsible committee on human experimentation (institutional and national) and with the Helsinki Declaration (as revised in 2013). The present study was performed after obtaining the permission of the Yokohama City University Bioethics Committee for Human Genome and Gene analysis (November 7, 2017; approval number, A171100002) and written informed consent was obtained from all participants.

Open Access Statement: This is an Open Access article distributed in accordance with the Creative Commons Attribution-NonCommercial-NoDerivs 4.0 International License (CC BY-NC-ND 4.0), which permits the noncommercial replication and distribution of the article with the strict proviso that no changes or edits are made and the original work is properly cited (including links to both the formal publication through the relevant DOI and the license). See: https://creativecommons.org/licenses/by-nc-nd/4.0/.

\section{References}

1. Okura Y, Ramadan MM, Ohno Y, et al. Impending epidemic: future projection of heart failure in Japan to the year 2055. Circ J 2008;72:489-91.

2. Shimokawa H, Miura M, Nochioka K, et al. Heart failure as a general pandemic in Asia. Eur J Heart Fail 2015;17:884-92.

3. Lynn J. Perspectives on care at the close of life. Serving patients who may die soon and their families: the role of hospice and other services. JAMA 2001;285:925-32.

4. Allen LA, Stevenson LW, Grady KL, et al. Decision making in advanced heart failure: a scientific statement from the American Heart Association. Circulation 2012;125:1928-52.

5. The Japanese Circulation Society. Guidelines for Diagnosis and Treatment of Acute and Chronic Heart Failure (JCS 2017/JHFS 2017) [in Japanese] 2018. Available online: http://www.j-circ.or.jp/guideline/pdf/ JCS2017_tsutsui_h.pdf

6. Kirchhoff KT, Hammes BJ, Kehl KA, et al. Effect of a disease-specific advance care planning intervention on end-of-life care. J Am Geriatr Soc 2012;60:946-50.

7. Denvir MA, Cudmore S, Highet $G$, et al. Phase 2 Randomised Controlled Trial and Feasibility Study of Future Care Planning in Patients with Advanced Heart Disease. Sci Rep 2016;6:24619.

8. El-Jawahri A, Paasche-Orlow MK, Matlock D, et al. Randomized, Controlled Trial of an Advance Care Planning Video Decision Support Tool for Patients With Advanced Heart Failure. Circulation 2016;134:52-60.

9. Van Scoy LJ, Green MJ, Dimmock AE, et al. High satisfaction and low decisional conflict with advance care planning among chronically ill patients with advanced 
chronic obstructive pulmonary disease or heart failure using an online decision aid: A pilot study. Chronic Illn 2016;12:227-35.

10. Heyland DK, Barwich D, Pichora D, et al. Failure to engage hospitalized elderly patients and their families in advance care planning. JAMA Intern Med 2013;173:77887.

11. Ahluwalia SC, Levin JR, Lorenz KA, et al. "There's no cure for this condition": how physicians discuss advance care planning in heart failure. Patient Educ Couns 2013;91:200-5.

12. Slort W, Schweitzer BP, Blankenstein AH, et al. Perceived barriers and facilitators for general practitioner-patient communication in palliative care: a systematic review. Palliat Med 2011;25:613-29.

13. McIlvennan CK, Allen LA. Palliative care in patients with heart failure. BMJ 2016;353:11010.

14. You JJ, Aleksova N, Ducharme A, et al. Barriers to Goals of Care Discussions With Patients Who Have Advanced Heart Failure: Results of a Multicenter Survey of Hospital-Based Cardiology Clinicians. J Card Fail 2017;23:786-93.

15. Kavalieratos D, Mitchell EM, Carey TS, et al. "Not the 'grim reaper service'": an assessment of provider knowledge, attitudes, and perceptions regarding palliative care referral barriers in heart failure. J Am Heart Assoc 2014;3:e000544.

16. Aleksova N, Demers C, Strachan PH, et al. Barriers to goals of care discussions with hospitalized patients with advanced heart failure: feasibility and performance of a novel questionnaire. ESC Heart Fail 2016;3:245-52.

17. Sato Y. Multidisciplinary management of heart failure just beginning in Japan. J Cardiol 2015;66:181-8.

Cite this article as: Tokunaga-Nakawatase Y, Ochiai R, Sanjo M, Tsuchihashi-Makaya M, Miyashita M, Ishikawa T, Watabe S. Perceptions of physicians and nurses concerning advanced care planning for patients with heart failure in Japan. Ann Palliat Med 2020;9(4):1718-1731. doi: 10.21037/apm-19-685
18. Matsuoka S, Okumura Y, Ichikawa K, et al. Cardiologists' and Nurses' Recognition of End-Stage Heart Failure: A National Survey. J Cardiol Jpn 2011;6:115-21.

19. Kuragaichi T, Kurozumi Y, Ohishi S, et al. Nationwide Survey of Palliative Care for Patients With Heart Failure in Japan. Circ J 2018;82:1336-43.

20. Mizuno A, Miyashita M, Hayashi A, et al. Potential palliative care quality indicators in heart disease patients: A review of the literature. J Cardiol 2017;70:335 41.

21. Ponikowski P, Voors AA, Anker SD, et al. 2016 ESC Guidelines for the diagnosis and treatment of acute and chronic heart failure: The Task Force for the diagnosis and treatment of acute and chronic heart failure of the European Society of Cardiology (ESC) Developed with the special contribution of the Heart Failure Association (HFA) of the ESC. Eur Heart J 2016;37:2129-200.

22. Yancy CW, Jessup M, Bozkurt B, et al. 2013 ACCF/AHA guideline for the management of heart failure: a report of the American College of Cardiology Foundation/ American Heart Association Task Force on practice guidelines. Circulation 2013;128:e240-327.

23. Sudore RL, Lum HD, You JJ, et al. Defining Advance Care Planning for Adults: A Consensus Definition From a Multidisciplinary Delphi Panel. J Pain Symptom Manage 2017;53:821-32.e1.

24. The Japanese Circulation Society. Statement for endstage cardiovascular care (JCS 2010). Available online: http://search.jamas.or.jp/link/ui/2012266802

25. Studdert DM, Mello MM, Burns JP, et al. Conflict in the care of patients with prolonged stay in the ICU: types, sources, and predictors. Intensive Care Med 2003;29:1489-97. 